\title{
Unsubstituted phenothiazine as a superior water-insoluble mediator for oxidases
}

\author{
Alina Sekretaryova, Mikhail Vagin, Valerio Beni, Anthony P.F. Turner and Arkady A. \\ Karyakin
}

\section{Linköping University Post Print}

\section{Tweet}

N.B.: When citing this work, cite the original article.

Original Publication:

Alina Sekretaryova, Mikhail Vagin, Valerio Beni, Anthony P.F. Turner and Arkady A. Karyakin, Unsubstituted phenothiazine as a superior water-insoluble mediator for oxidases, 2014, Biosensors \& bioelectronics, (53), 275-282.

http://dx.doi.org/10.1016/j.bios.2013.09.071

Copyright: Elsevier http://www.elsevier.com/

Postprint available at: Linköping University Electronic Press http://urn.kb.se/resolve?urn=urn:nbn:se:liu:diva-100391 


\title{
Unsubstituted Phenothiazine as a Superior Water-insoluble Mediator for Oxidases
}

Alina N. Sekretaryova ${ }^{1,2}$, Mikhail Yu. Vagin ${ }^{2}$, Valerio Beni ${ }^{2}$, Anthony P.F. Turner ${ }^{2}$, Arkady A. Karyakin $^{1}$

${ }^{1}$ Faculty of Chemistry, M.V. Lomonosov Moscow State University, Lenin's Hills, 119991, Moscow, Russia

${ }^{2}$ Department of Physics, Chemistry and Biology, Linköping University, SE-581 83, Linköping, Sweden

\begin{abstract}
The mediation of oxidases: glucose oxidase (GOx), lactate oxidase (LOx) and cholesterol oxidase (ChOx) by a new electron shuttling mediator, unsubstituted phenothiazine (PTZ), was studied. Cyclic voltammetry and rotating-disk electrode measurements in nonaqueous media were used to determine the diffusion characteristics of the mediator and the kinetics of its reaction with GOx, giving a second-order rate constant of $7.6 \times 10^{3} \mathrm{M}^{-1} \mathrm{~s}^{-1}$ to $2.1 \times 10^{4} \mathrm{M}^{-1} \mathrm{~s}^{-1}$ for water - acetonitrile solutions containing $5 \%$ to $15 \%$ water. These values are in the range reported for commonly used azine-type mediators, indicating that PTZ is able to function as an efficient mediator. PTZ and GOx, LOx and ChOx were successfully co-immobilized in sol-gel membrane on a screen-printed electrode to construct glucose, lactate and cholesterol biosensors, respectively, which were then optimised in terms of stability and sensitivity. The electrocatalytic oxidation responses showed a dependence on substrate concentration ranging from 0.6 to $32 \mathrm{mM}$ for glucose, from 19 to $565 \mathrm{mM}$ for lactate and from 0.015 to $1.0 \mathrm{mM}$ for cholesterol detection. Oxidation of substrates on the surface of electrodes modified with PTZ and enzyme membrane was investigated with double-step chronoamperometry and the results showed that the PTZ
\end{abstract}


displays excellent electrochemical catalytic activities even when immobilised on the surface of the electrode.

\section{Highlights:}

- The kinetics of the electrocatalytic oxidation of glucose with GOx mediated by a new electron shuttling mediator, PTZ, was studied.

- PTZ delivers superior potential performance among azine-type redox mediators for GOx.

- $\quad$ PTZ and GOx, LOx and ChOx were successfully co-immobilized in sol-gel membrane on a screen-printed electrode to construct glucose, lactate and cholesterol biosensors, respectively.

- Second-order rate constants for the reaction between the mediator and variety of oxidases co-immobilised inside a sol-gel membrane were obtained by chronoamperometry.

Keywords: phenothiazine, electron transfer mediator, enzyme biosensor, glucose oxidase, lactate oxidase, cholesterol oxidase. 


\section{INTRODUCTION}

Amperometric biosensors based on oxidases have been described for over 80 analytes (May 1999; Solná et al. 2005). Oxidases have evolved to catalyse the oxidation of many different substrates and are integral to the biological pathways of plants, animals, and bacteria. Among them the flavin adenine dinucleotide (FAD) dependent GOx (Cash and Clark 2010; Li et al. 2011; Shan et al. 2010) and cholesterol oxidase (ChOx) (Arya et al. 2008; Fang et al. 2011) as well as flavin mononucleotide (FMN) dependent lactate oxidase (LOx) (Pereira et al. 2011; Romero et al. 2010) are suitable candidates for the recognition of important physiologic analytes. The use of mediators to create disposable amperometric biosensors for analytes such as glucose has proved to be a highly successful strategy and a major commercial success (Newman and Turner 2005). Direct electron exchange between an electrode surface and the deeply buried prosthetic group of large enzymes such as glucose oxidase $(160 \mathrm{kDa})$ is hampered (Wilson and Turner 1992). Electron transfer mediators facilitate electrical communication between the active site of a redox protein and the electrode thus decreasing the kinetic barrier for electron transfer (Cui et al. 2007); (Liu et al. 2009).

A typical electrocatalytic reaction for a mediated oxidase proceeds in three steps. The enzyme takes part in first redox reaction with the substrate and is then re-oxidised by the mediator. Finally the mediator is re-oxidised by the electrode. In this context, a variety of reversible electron acceptors have been studied as mediators for redox enzymes. The electron transfer mediator has to satisfy the following requirements: (i) the redox potential of the mediator should be small enough to avoid interfering electrochemical reactions, (ii) both oxidised and reduced forms of mediator should be stable enough and (iii) the second-order rate constant for reaction between mediator and enzyme should be high enough to minimise competition with oxygen (Cardosi and Turner 1987). Consequently, the choice of the mediator is critical to achieve high sensitivity and selectivity. 
Ferrocene and its derivatives, ferri/ferrocyanide, complexes of transition metals such as osmium and ruthenium as well as redox organic dyes are widely used redox mediators for oxidases. Ferri/ferrocyanide is one of the most commonly used and efficient soluble inorganic mediators (Dubinin et al. 1991; Jaffari and Turner 1997; Shul'ga et al. 1994). However due to its small size and high solubility, it easily diffuses away from the electrode surface into the bulk solution, which reduces long-term operational stability and hampers its application in both continuous laboratory analysers and implantable probes. The less soluble ferrocene derivatives provide a partial solution to this problem and have achieved considerable success in commercial home-use devices, but the ferrocinium ion is still soluble (Cass et al. 1984). Tertrathiafulvalene has been proposed as one alternative to ferrocene derivatives as an insoluble mediator for amperometric biosensors (Palleschi and Turner 1990); (Turner 1987); (Murthy and Anita 1996). In spite of their high efficiency in mediating the electron transfer of oxidases, osmium and ruthenium complexes (Motonaka et al. 1994; Ohara et al. 1993) have essential drawbacks due to their high toxicity. Several redox dyes such as methylene green (Upadhyay et al. 2009), methylene blue (Wang and Hasebe 2012), meldola blue (Pereira et al. 2011), celestine blue (Noorbakhsh et al. 2008), phenazine (Liu et al. 1997; Ohfuji et al. 2004), thionine (Huang et al. 2011), azure B (Shan et al. 2003), toluidine blue (Yao and Shiu 2007) can be used as electron transfer mediators for oxidases when immobilised on the electrode surfaces. The main drawback of organic dyes-based biosensors is the leaching out of catalytic materials from the electrode surface. Thus many studies have been done to improve the operational stability of such devices. In our previous work (Sekretaryova et al. 2012) we have evaluated the possibility to eliminate mediator leakage by incorporating a new hydrophobic mediator, unsubstituted phenothiazine (PTZ), within a robust water-insoluble sol-gel membrane of siloxanes.

In the present study, the protocol for enzyme co-immobilisation with PTZ into a siloxane sol-gel membrane has been expanded to different oxidases. Kinetic studies of PTZ-mediated bioelectrocatalysis by variety of methods demonstrated the excellent operational performance of 
the mediator as an electron shuttle between the active site of these various oxidases and the electrode. The entrapment of PTZ into a siloxane sol-gel matrix led to the development of a robust and flexible environment for immobilisation of different oxidases: GOx, LOx and ChOx. A reagentless biosensor based on mediated $\mathrm{ChOx}$ has been further characterised to show superior analytical performance compared to other biosensors for cholesterol measurement.

\section{EXPERIMENTAL}

\section{Materials}

All inorganic salts, organic solvents and Triton X-100 were obtained at the highest purity from Sigma Aldrich (Sweden). $\gamma$-Aminopropyltriethoxysiloxane was obtained from Reachim (Moscow, Russia). Glucose oxidase type VII from Aspergillus niger (lyophilised powder, $\geq 100$ $\mathrm{U} \mathrm{mg}^{-1}$ solid), Cholesterol oxidase from Streptomyces $s p$. (lyophilised powder, $\geq 20 \mathrm{U} \mathrm{mg}^{-1}$ protein), Cholesterol (powder, BioReagent, suitable for cell culture, $\geq 99.0 \%$ ), Lactate oxidase from Pediococcus sp. (lyophilized powder, $\geq 20 \mathrm{U} \mathrm{mg}^{-1}$ solid ), Sodium L-lactate ( $\geq 99.0 \%$ (NT)) were purchased from Sigma Aldrich (Sweden). D-glucose was obtained from AnalaR (England). All chemicals were of reagent grade and used as received. Experiments were carried out with Milli-Q water from a Millipore Milli-Qsystem.

An aqueous stock solution of $0.5 \mathrm{M}$ glucose was prepared in phosphate buffer $(0.05 \mathrm{M}$, $\mathrm{pH}$ 7.0) and left for at least 24 hours at room temperature before use to allow equilibration of the anomers. The solution was stored at $4{ }^{\circ} \mathrm{C}$.

A stock solution of $15 \mathrm{mM}$ cholesterol was prepared as previously described (Vidal et al. 2004) in phosphate buffer $(0.05 \mathrm{M}, \mathrm{pH} 6.8)$ containing $15 \%(\mathrm{w} / \mathrm{w})$ of Triton $\mathrm{X}-100$ in a thermostated bath at $65{ }^{\circ} \mathrm{C}$. This solution was stored at $4{ }^{\circ} \mathrm{C}$ in the dark and was stable for at least 10-15 days (until turbidity was observed). More dilute working solutions of cholesterol were prepared by dilution of the stock solution using a $0.05 \mathrm{M}$ phosphate buffer solution containing $1 \%(\mathrm{w} / \mathrm{w})$ of Triton $\mathrm{X}-100$. 
A stock solution of $4 \mathrm{M}$ lactate was prepared by dissolving of the proper amount of sodium lactate in phosphate buffer $(0.05 \mathrm{M})$ solution $\mathrm{pH}$ 6.0. The solution was stored at $4{ }^{\circ} \mathrm{C}$.

\section{Apparatus}

An Autolab type III bipotentiostat system (Autolab, EcoChemie, Netherlands) and EmStat USB potentiostat (Palm Instruments, Netherlands) were employed for cyclic voltammetry $(\mathrm{CV})$ and chronoamperometric measurements. The screen-printed electrode system with graphite working electrode (diameter $1.9 \mathrm{~mm}$ ), graphite auxiliary electrode, and $\mathrm{Ag} / \mathrm{AgCl}$ reference electrode were purchased from Rusens LTD (Moscow, Russia) and were characterised by reversible voltammograms of ferro/ferrycyanoferrate couple in neutral media. Rotating disk electrode (RDE) voltammetry was performed using a potentiostat supplied by Ivium Technologies (USA) using a conventional three-electrode cell configuration. Glassy carbon (GC) rotating disk electrode (diameter $5 \mathrm{~mm}$, Pine Instrument) was used as the working electrode with rotation control (Pine Instrument).

\section{Measurements in acetonitrile}

GC electrodes were successively polished with alumina powders $(1.0$ and $0.05 \mu \mathrm{m})$ followed by ultrasonication in distilled water and washing with ethanol. Measurements were carried out in $0.1 \mathrm{M} \mathrm{LiClO}_{4}$ acetonitrile solution containing $1 \mathrm{mM}$ PTZ. A platinum wire and an $\mathrm{Ag}^{+} / \mathrm{Ag}\left(0.01 \mathrm{M} \mathrm{AgNO}_{3}, 0.1 \mathrm{M} \mathrm{TBAClO}_{4}\right.$ in acetonitrile) electrode were used as the auxiliary and reference electrodes for all measurements in acetonitrile, respectively. Cyclic voltammogram of ferrocene ( $1 \mathrm{mM}$ in acetonitrile) has been recorded on glassy carbon electrode as a test experiment to check the validity of organic reference electrode. Glucose oxidase and glucose aqueous solutions were added into the cell. Final water contents in CV and RDE measurements were $15 \%$ and $5 \%$ respectively. 


\section{Enzyme immobilisation}

Enzyme immobilisation was carried out from water-organic mixture with the high content of organic solvent (Yashina et al. 2010). Aqueous solution of the appropriate enzyme (GOx or ChOx or LOx) was suspended in an isopropanol solution of $\gamma$-aminopropyltriethoxysiloxane containing PTZ. The resulting mixture $(2-3 \mu \mathrm{L})$ was applied with a syringe onto the working electrode covering its entire surface and dried in a refrigerator $\left(4{ }^{\circ} \mathrm{C}\right)$. The biosensors response was assayed in $0.05 \mathrm{M}$ phosphate buffer solutions containing $0.1 \mathrm{M} \mathrm{KCl}$ as a supporting electrolyte. The $\mathrm{pH}$ of the buffer solutions were selected to be appropriate for the enzymes used (Table 1).

\section{Table 1}

Composition of the resulting mixture for different biosensors and $\mathrm{pH}$ of buffer solutions for electrochemical measurements.

\begin{tabular}{|c|c|c|c|c|}
\hline $\begin{array}{l}\text { Oxidase based } \\
\text { biosensor }\end{array}$ & $\begin{array}{l}\text { Enzyme } \\
\text { concentration, } \\
\mathrm{mg} \mathrm{mL}^{-1}\end{array}$ & $\begin{array}{l}\text { PTZ } \\
\text { concentration, } \\
\text { M }\end{array}$ & $\begin{array}{l}\text { Siloxane } \\
\text { concentration, } \\
\%\end{array}$ & $\begin{array}{l}\text { pH of the } \\
\text { buffer } \\
\text { solutions }\end{array}$ \\
\hline Glucose oxidase & 1.5 & 0.05 & 1.0 & 7.0 \\
\hline Lactate oxidase & 1.0 & 0.05 & 0.3 & 6.0 \\
\hline Cholesterol oxidase & 1.5 & 0.05 & 0.3 & 6.8 \\
\hline
\end{tabular}

\section{RESULTS AND DISCUSSION}

Presumably because of its insolubility in water, PTZ has not been previously explored as a mediator for oxidases. However, in order to ensure the electron transfer, the mediator must be present in both oxidised and reduced forms, which must remain in the vicinity of electrode. In some formats, this means that the mediator must be insoluble. Hence, this is the first detailed study of its diffusion characteristics and electrochemical kinetics in a mediated enzymatic reaction. 


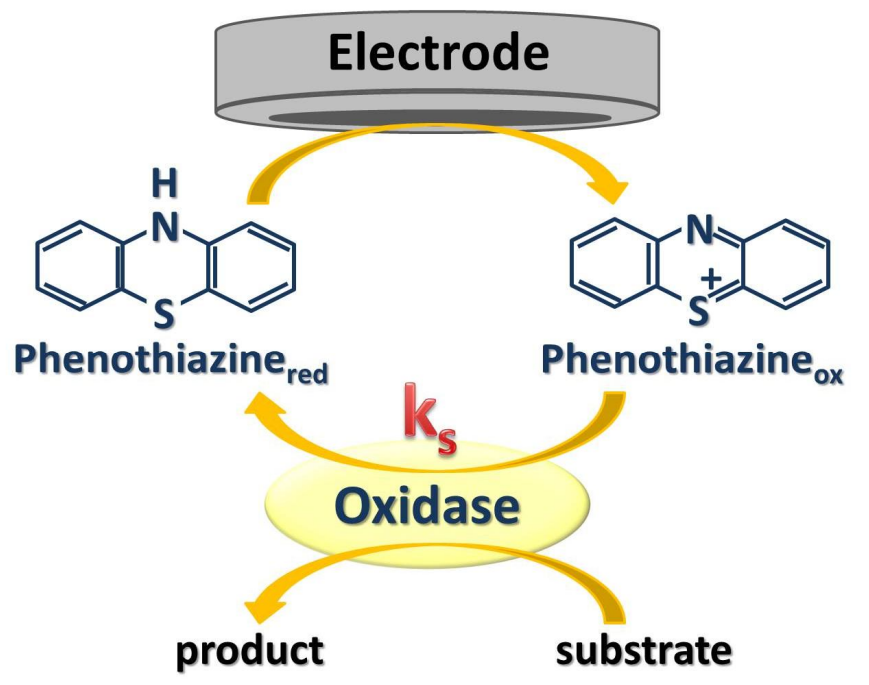

Sheme 1. Scheme of the enzymatic reaction catalysed by PTZ.

\section{Diffusion Characteristics of PTZ in acetonitrile}

Due to water-insolubility of unsubstituted PTZ $\left(25 \mathrm{mg} \mathrm{L}^{-1}, 25^{\circ} \mathrm{C}\right)$ it was impossible to carry out experiments in aqueous media. Therefore, a water-acetonitrile mixture has been used as a media for electrochemical measurements. Figure 1 A shows a family of CV curves of PTZ solution in acetonitrile obtained with varied scan rates. The ratio between anodic and cathodic peak currents $i_{p a} / i_{p c}$ was higher than 1 . However the application of modified equation suggested by Nicholson (Nicholson 1965)

$$
\frac{i_{p c}}{i_{p a}}=\frac{\left(i_{p c}\right)_{0}}{\left(i_{p a}\right)_{0}}+\frac{0.485\left(i_{\lambda}\right)_{0}}{i_{p a}}+0.086
$$

where $\left(i_{p a}\right)_{0}$ is the peak current for the forward process, $\left(i_{\lambda}\right)_{0}$ is the absolute current at the switching potential, and $\left(i_{p c}\right)_{0}$ is the uncorrected return peak current measured from the current axis, revealed the ratio of the anodic and cathodic peak currents close to $1.0(0.97-1.08)$ for the scan rates 5-30 $\mathrm{mV} \mathrm{s}^{-1}$. These observations show that the PTZ dissolved in the acetonitrile underwent reversible electron exchanges with the electrode (Randles 1948).

A linear dependence of the peak currents on the square root of the scan rate (Inset to Figure $1 \mathrm{~A}$ ) indicates diffusion-controlled mechanism of electrode reaction. As the potential difference between observed peaks was independent of scan rate illustrating a pure diffusion control, the diffusion coefficient of PTZ was estimated to be $(2.0 \pm 0.2) \times 10^{-6} \mathrm{~cm}^{2} \mathrm{~s}^{-1}$ from the 
slope of the linear regression of the anodic peak currents (Inset to Figure $1 \mathrm{~A}$ ) according to Randles-Sevcik equation (Bard 1980):

$$
I_{p}=\frac{0.4463 n^{2 / 3} F^{2 / 3} A C D^{1 / 2} v^{1 / 2}}{R^{1 / 2} T^{1 / 2}}
$$

where $I_{p}$ is peak current (A), $n$ - number of transferring electrons ( 2 in case of PTZ), $v$-scan rate $\left(\mathrm{V} \mathrm{s}^{-1}\right), F$ - Faraday's constant $\left(96485 \mathrm{C} \mathrm{mol}^{-1}\right), A$ - electrode area $\left(\mathrm{cm}^{2}\right), D$ - diffusion coefficient $\left(\mathrm{cm}^{2} \mathrm{~s}^{-1}\right), R$ - universal gas constant $\left(8.314 \mathrm{~J} \mathrm{~mol}^{-1} \mathrm{~K}^{-1}\right)$, and $T$ - absolute temperature $(\mathrm{K})$.
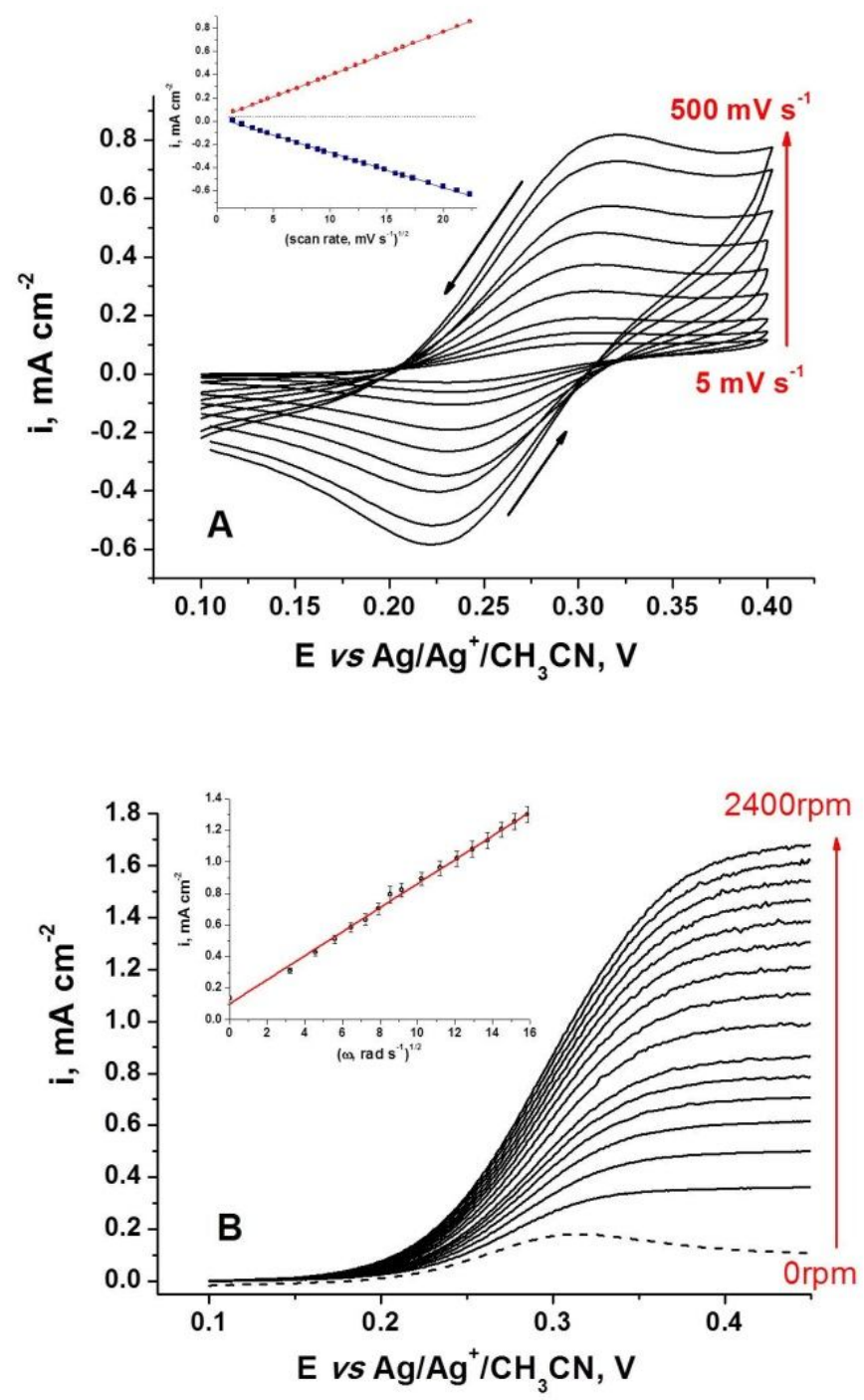

Figure 1. Diffusion characteristic of $1 \mathrm{mM}$ PTZ in $0.1 \mathrm{M} \mathrm{LiClO}_{4}$ acetonitrile solution. A: Cyclic voltammograms at GCE, scan rates 5, 10, 20, 50, 90, 150, 250, 400 and $500 \mathrm{mV} \mathrm{s}^{-1}$. Insert: dependencies of peak currents ((O) anodic, ( $)$ cathodic) on square root of scan rate. B: Steady-state current-potential curves at RDE, rotating rates from 0 (dash curve) to $2400 \mathrm{rpm}$, scan rate $20 \mathrm{mV} \mathrm{s}^{-1}$. Insert: Levich plot of limiting current. 
As a reference approach, the diffusion coefficient for PTZ was also determined from RDE measurements under steady-state conditions (Haberland and Landsberg 1966). Figure 1 B shows a series of voltammograms for the oxidation of PTZ in acetonitrile obtained at rotating disk electrode. The typical Levich plot (Inset to Figure 1 B), i.e. the dependence of the limiting current on the square root of rotation rate, allows us to estimate the diffusion coefficient by Levich equation (Levich 1962):

$$
I=0.62 n F A D^{2 / 3} v^{-1 / 6} C \omega^{1 / 2}
$$

where $C$ is the bulk concentration of mediator, $D-$ diffusion coefficient, $v-$ the kinematic viscosity of the solution $\left(0.004536 \mathrm{~cm}^{2} \mathrm{~s}^{-1}\right.$ for $0.1 \mathrm{M} \mathrm{LiClO}_{4}$ in acetonitrile (Tsushima et al. 1994)) and $n$ - number of electron transferred. From the slope the value of diffusion coefficient was determined to be $(3.8 \pm 0.3) \times 10^{-6} \mathrm{~cm}^{2} \mathrm{~s}^{-1}$, which is in a good agreement with stationary electrode measurements.

A direct comparison of the diffusion coefficients of PTZ with its water-soluble derivatives, commonly used as enzyme mediators, is inappropriate due to the different media employed for measurements. However, the values obtained are comparable to the values for typical azine-type mediators measured in water-ethanol mixtures $\left(1.8-3.7 \times 10^{-6} \mathrm{~cm}^{2} \mathrm{~s}^{-1}\right)$ (Chakraborty et al. 2010) and comparable to the value of the diffusion coefficient for Methylene Blue in aprotic solvent $6.2 \times 10^{-6} \mathrm{~cm}^{2} \mathrm{~s}^{-1}$ (Wopschall and Shain 1967).

\section{Kinetics of GOx biocatalysis mediated by PTZ}

The cyclic voltammograms recorded in the acetonitrile solution of GOx and PTZ showed an increase of anodic current in presence of glucose (Inset to Figure 2). This effect illustrates the electrocatalytic oxidation of glucose with GOx mediated with PTZ. The whole electrochemical process can be described according to the following reaction mechanism reported previously (Sekretaryova et al. 2012):

Glucose $+\mathrm{GOx}_{\mathrm{ox}}(\mathrm{FAD}) \rightarrow$ Gluconolactone $+\mathrm{GOx}_{\text {red }}\left(\mathrm{FADH}_{2}\right)(1)$ 
$\mathrm{GOx}_{\mathrm{red}}\left(\mathrm{FADH}_{2}\right)+\mathrm{PTZ}_{\mathrm{ox}} \stackrel{k_{g}}{\rightarrow} \mathrm{GOx}_{\mathrm{ox}}(\mathrm{FAD})+\mathrm{PTZ}_{\mathrm{red}}+2 \mathrm{H}^{+}(2)$

$\mathrm{PTZ}_{\mathrm{red}} \rightarrow \mathrm{PTZ}_{\mathrm{ox}}+2 \mathrm{e}^{-}$

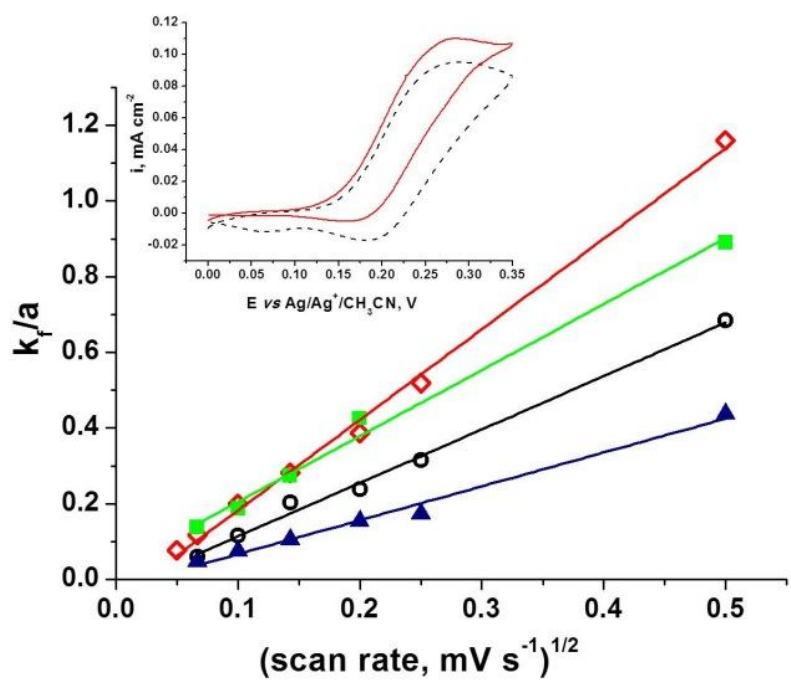

Figure 2. Electrocatalytic oxidation of glucose by PTz-mediated GOx in acetonitrile by cyclic voltammetry. Catalytic parameters as a function of inverse scan rate upon addition of GOx at a final concentration of $(\Delta) 1.25 \mu \mathrm{M},(\circ) 1.87 \mu \mathrm{M}$, ( ) $2.5 \mu \mathrm{M}, 3.12 \mu \mathrm{M}(\diamond)$. Inset: Cyclic voltammograms of $1 \mathrm{mM} \mathrm{PTZ}$ and $50 \mathrm{mM}$ glucose in $0.1 \mathrm{M} \mathrm{LiClO}_{4}$ acetonitrile solution (15\% of water) before (dash curve) and after (solid curve) addition of GOx $\left(0.2 \mathrm{mg} \mathrm{mL}^{-1}\right)$; GC electrode, scan rate $2 \mathrm{mV} \mathrm{s}^{-1}$.

In order to enhance the sensitivity and minimise competition with dissolved oxygen, an electron transfer mediator should possess high values of second-order rate constant $k_{s}$ in Eq. (2). In order to make an interaction between mediator and enzyme (reaction 2) the rate-determining step and, therefore, assess the second-order rate constant from voltammetry measurements, it is necessary to fulfill two conditions. First, in order to avoid limitation in reaction 1, the substrate concentration must be sufficiently higher than the $\mathrm{K}_{\mathrm{M}}(33 \mathrm{mM}$ (TSUGE et al. 1975)). Hence experiments were performed with a glucose concentration of $50 \mathrm{mM}$. Secondly, in order to avoid limitation in reaction 3 , the electron transfer step must be rapid enough to establish diffusion control. So the conditions for diffusion-controlled reversible PTZ oxidation in acetonitrile were ascertained in the following experiments.

The complete description of the use of cyclic voltammetry measurements to determine $k_{s}$ was first given by Nicholson and Shain (Nicholson and Shain 1964). Assuming all GOx is essentially in reduced state $\mathrm{GOx}_{\mathrm{red}}\left(\mathrm{FADH}_{2}\right)$ due to high glucose concentration, a pseudo-firstorder rate constant can be written as 


$$
k_{f}=k_{s}[G O x]=a \times\left(\frac{i_{c}}{i_{p}}\right)^{2}
$$

where $a=n F v / R T, v$ is a scan rate, $i_{c}$ and $i_{p}$ are catalytic and peak currents of PTZ measured in presence and in absence of substrate correspondingly. The plots of $k_{f} / a$ vs $1 / v$ were constructed for a series of GOx concentrations (Figure 2). The slopes were used to determine $\mathrm{k}_{\mathrm{f}}$. Finally, a plot of $k_{f} v s[\mathrm{GOx}]$ was used to calculate $k_{s}$. The value for $k_{s}$ was determined for PTZ to be $(2.1 \pm$ $0.2) \times 10^{4} \mathrm{M}^{-1} \mathrm{~s}^{-1}$.

RDE voltammetry is a more convenient tool for the kinetic study of electrocatalytic reactions than cyclic and linear sweep voltammetries (Andrieux et al. 1980). Therefore, this method was applied for the kinetic study of glucose oxidation by GOx mediated with PTZ in acetonitrile solution. Typical voltammograms recorded at rotating GC disk electrode are presented at Figure 3. The complete oxidation of PTZ is indicated by a steady-state current being achieved at $0.35 \mathrm{~V}$ (Curve 1 at Figure 3). The addition of GOx did not deliver any significant changes in the observed currents (Curve 2 at Figure 3). Subsequent addition of glucose led to an oxidation current increase due to mediated electrocatalysis (Curve 3 at Figure 3). The additions of glucose up to concentrations below one order of mediator concentration (less than $10 \mathrm{mM}$ ) did not display significant electrocatalysis by PTZ (data not shown) due to the change of the rate determining step. When $\omega(D / v)<<3 k_{s} C$ (where $\omega$ is an angular frequency of electrode rotation $\left(\operatorname{rad~s}^{-1}\right)$ and $k_{s}-$ a second-order rate constant as in Eq. (2)), the ratio of the limiting kinetic current $I_{c a t}$ to the unperturbed limiting current (Levich's current) $I_{\text {Lev }}$ measured in presence and in absence of substrate correspondingly, is found using the following equation:

$$
\frac{I_{c a t}}{I_{\text {Lev }}}=1.61\left(\frac{v}{D}\right)^{1 / 6}\left(\frac{k_{s} C}{\omega}\right)^{1 / 2}
$$

The value of $k_{s}$ can be evaluated from the slope of the plot $\mathrm{I}_{\text {cat }} / \mathrm{I}_{\text {Lev }} v s \omega^{-1 / 2}$ (Figure 3, insert) and was determined to be $(7.6 \pm 1.2) \times 10^{3} \mathrm{M}^{-1} \mathrm{~s}^{-1}$. 


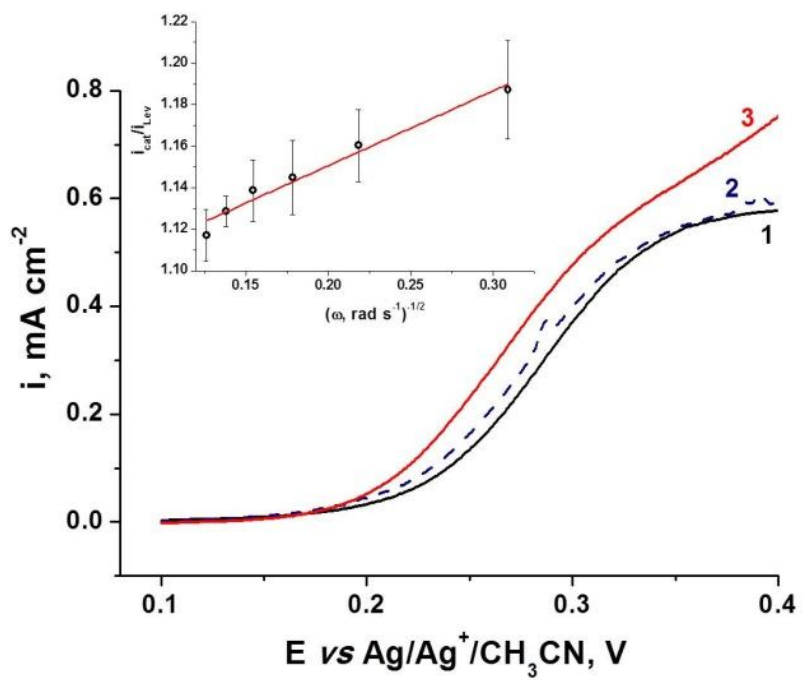

Figure 3. Electrocatalytic oxidation of glucose by PTZ-mediated GOx in acetonitrile by RDE voltammetry. Curve 1: $1 \mathrm{mM} \mathrm{PTZ}$ in $0.1 \mathrm{M} \mathrm{LiClO}_{4}$ in acetonitrile (5\% of water, GC electrode, rotation speed $400 \mathrm{rpm}$, scan rate $\left.20 \mathrm{mV} \mathrm{s}^{-1}\right)$; Curve 2 (dotted): after addition of GOx $\left(0.035 \mathrm{mg} \mathrm{mL}^{-1}\right)$; Curve 3: after addition of glucose $(10 \mathrm{mM})$. Insert: Relationship between $I_{\text {cal }} / I_{\text {Lev }} v s$ (rotation rate, $\left.\omega\right)^{-1 / 2}$.

The values of rate constant obtained from $\mathrm{CV}$ and $\mathrm{RDE}$ voltammetry measurements were compared with data for previously reported and commonly used GOx mediators (Table 2). The $\mathrm{k}_{\mathrm{s}}$ obtained is slightly lower than constants for ferrocene derivates, but is still high enough to minimise competition with oxygen $\left(k_{s}^{O 2}=2 \times 10^{2} \mathrm{M}^{-1} \mathrm{~s}^{-1}\right.$ (Bright and Gibson 1967)). The obtained value of $k_{s}$ for PTZ is comparable to, or greater than those previously reported for azine-type mediators of GOx. It should also be noted that all these mediators are water soluble, at least in one of their forms (oxidised or reduced) and can therefore diffuse away from the electrode surface into the bulk solution, and this would preclude, for instance, their use as implantable probes or for continuous monitoring. Thus the present study demonstrates that PTZ is an effective electron transfer mediator for GOx as well as possessing some potential advantages such as low toxicity and water-insolubility. 


\section{Table 2}

Comparison of kinetic data for homogeneous catalysis of glucose oxidase with different soluble redox mediators at $\mathrm{pH} 7.0$ (unless otherwise specified).

\begin{tabular}{lll}
\hline Mediator & $\boldsymbol{k}_{\boldsymbol{s}}, \mathbf{M}^{-\mathbf{1}} \mathbf{s}^{-\mathbf{1}}$ & Ref. \\
\hline Osmium bipyridine-pyridine & $2.2 \times 10^{5}$ & (Flexer et al. 2008) \\
carboxylic acid & $6.0 \times 10^{6}$ & (Bourdillon et al. \\
Ferrocenemethanol & $1.5 \times 10^{5}$ & 1993) \\
Ferrocenemonocarboxylic & $9.5 \times 10^{4}$ & (Liaudet et al. 1990) \\
Ferrocenemonosulfonate & $1.0 \times 10^{3}$ & (Kulys et al. 1994) \\
Nickelocene & $6.3 \times 10^{4}$ & \\
l-(1-piperidine)-4-(4- & & \\
morpholine)-benzene & $5.5 \times 10^{3}$ & (Kulys et al. 1994) \\
Azines & $1.0 \times 10^{2}$ & (Heller and Feldman \\
Methylene green & $1.6 \times 10^{4}$ & 2008) \\
Methylene blue & $4.0 \times 10^{2}$ & \\
Thionine & $9.8 \times 10^{2}$ & This work \\
Brilliant cresyl blue & $2.1 \times 10^{4}$ (from CV measurements) \\
Azure & $7.6 \times 10^{3}$ (from RDE measurements) & \\
Phenothiazine* & & \\
\hline
\end{tabular}

*kinetic data obtained in acetonitrile.

\section{GOx stability in acetonitrile}

Due to low solubility of unsubstituted PTZ in water, a water-organic mixture with a high content of organic solvent was used for the electrochemical measurements. Such media might cause the loss of enzyme activity, which could affect the observed kinetics. Therefore, the stability of GOx in water-acetonitrile mixtures was studied.

Voltammetry was used to assess enzyme stability in water-acetonitrile solution. Cyclic voltammetry at a stationary electrode with slow scan rate $\left(2 \mathrm{mV} \mathrm{s}^{-1}\right)$ showed less than $5 \%$ decrease of observed catalytic current for glucose oxidation with mediated GOx after 20 minutes (Figure $1 \mathrm{SA}$ ). Voltammetry at RDE showed less than $10 \%$ catalytic current decrease after 30 minutes (Figure $1 \mathrm{SB}$ ). The half-life of GOx in water-acetonitrile mixtures with a water content of $15 \%$ and $5 \%$, assessed from cyclic voltammetry and RDE voltammetry, were $160 \pm 10$ minutes and $110 \pm 30$ minutes, correspondingly. These results indicate that loss of GOx activity in the water-organic solvent mixture was negligible during the time period of the experiments and values of rate constant obtained were not significantly affected by enzyme instability. The 
decrease of concentration of active sites due to enzyme transfer into nonaqueous media might decrease the apparent second-order rate constant. However, its values estimated from measurements in acetonitrile still are higher than observed for azine-type mediators.

\section{Immobilisation of different mediated oxidases}

Successful co-immobilisation of both GOx and PTZ by siloxane sol-gel membrane entrapment has been reported previously (Sekretaryova et al. 2012). In the present work, the same protocol of enzyme and mediator co-immobilisation was applied for the immobilisation of lactate and cholesterol oxidases into a robust and mediated matrix to produce lactate and cholesterol biosensors.

Siloxane gels with co-immobilised enzyme and mediator were deposited onto screenprinted graphite electrodes and optimised with respect to concentrations of all components to provide both the highest stability and response (Table 1). Analytical characteristics of the elaborated oxidase-based mediated biosensors were investigated by amperometry at anodic potential of catalytic current increase $(0.3 \mathrm{~V}$ vs $\mathrm{Ag} / \mathrm{AgCl} / 3 \mathrm{M} \mathrm{KCl})$ under constant stirring.

Figure $4 \mathrm{~A}$ displays the catalytic current responses of a glucose biosensor following injections of standard glucose solutions. Injection of glucose to produce a concentration range of $0.6-32.0 \mathrm{mM}$ resulted in a rapid and prominent anodic current response. The corresponding calibration curve of the glucose sensor (Inset to Figure $4 \mathrm{~A}$ ) exhibits a linear response in the concentration range from 0.6 to $10.5 \mathrm{mM}$, with a correlation coefficient of 0.994 and a dynamic range from 0.6 to $32 \mathrm{mM}$, which covers the physiological level of glucose in blood (Heller and Feldman 2008). The detection limit calculated as the standard deviation of the baseline current multiplied by three was estimated to be $1.2 \mu \mathrm{M}$, which is among the lowest recorded for mediated enzyme biosensors. The sensitivity over the linear range was $17.1 \pm 0.4 \mathrm{~mA} \mathrm{M}^{-1} \mathrm{~cm}^{-2}$, which is higher than the most advanced systems such as those based on osmium-based hydrogel (Ohara et al. 1993). 
Figure 4 B shows the amperometric response of a screen-printed electrode modified with LOx and PTZ co-immobilised into a siloxane sol-gel membrane on injection of standard lactate solutions. An initial steady-state current response was observed in the presence of $19 \mathrm{mM}$ lactate. The current increased with each lactate addition from 19 to $565 \mathrm{mM}$ (Inset to Figure 4 B). The detection limit was found to be $64 \mu \mathrm{M}$. The observed catalytic current was linear from $19 \mathrm{mM}$ to $265 \mathrm{mM}$ lactate, with a regression coefficient 0.997 and a slope of $5.6 \pm 0.8 \mathrm{~mA} \mathrm{M}^{-}$ ${ }^{1} \mathrm{~cm}^{-2}$. The dynamic range of the biosensor covers the physiological level of lactate in an exercise induced sweat (Derbyshire et al. 2012), which is attractive for sport medicine applications.

The corresponding response profile for ChOx-based biosensor on addition of cholesterol is shown in Figure $4 \mathrm{C}$. The spiked cholesterol solution caused an increase in oxidation current. A good linear relationship between current density and cholesterol concentration was obtained from 0.015 to $1 \mathrm{mM}$ cholesterol that corresponds to the free cholesterol concentrations in blood (Li et al. 2005). The sensitivity was found to be $40 \pm 2 \mathrm{~mA} \mathrm{M}^{-1} \mathrm{~cm}^{-2}(\mathrm{r}=0.995)$ and the detection limit $2.3 \mu \mathrm{M}$ (Inset to Figure $4 \mathrm{C}$ ). The sensitivity observed is among the highest reported values for mediated cholesterol biosensors and is 5 times higher than previously reported values for printed cholesterol biosensors using 1,10-phenanthroline-5,6-dione as electron transfer mediator (Fang et al. 2011). 

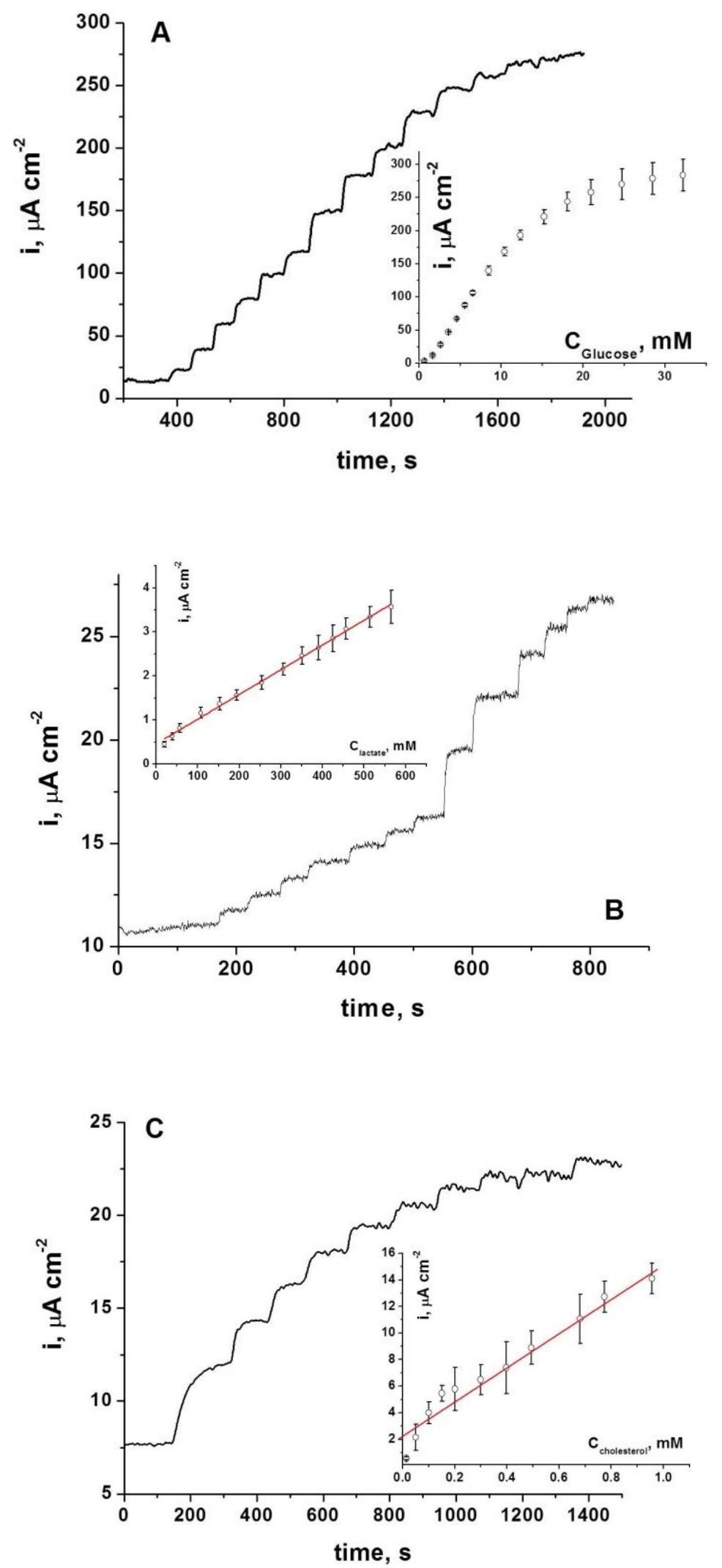

Figure 4. Analytical characterisation of enzyme biosensors. Amperometric responses of glucose biosensor (A, pH 7.0), lactate biosensor (B, pH 6.0) and cholesterol (C, $\mathrm{pH}$ 6.8). Screen-printed electrodes were modified with GOx- and PTZ-containing sol-gel membrane ( $1 \% \gamma$-aminopropylsilane, $50 \mathrm{mM}$ phetotiazine and $\left.1.5 \mathrm{mg} \mathrm{mL}^{-1} \mathrm{GOx}\right), 0.05 \mathrm{M}$ phosphate buffer with $0.1 \mathrm{M} \mathrm{KCl}$, applied potential $0.3 \mathrm{~V} v s$ $\mathrm{Ag} / \mathrm{AgCl} / 3 \mathrm{M} \mathrm{KCl}$. Insert: Calibration curves. 
The analytical performances of the current enzymatic biosensors are summarised in Table 3.

Table 3

Kinetic and analytical performances of elaborated biosensor with PTZ as mediator.

\begin{tabular}{lllll}
\hline Enzyme & $\boldsymbol{k}, \mathbf{M}^{-1} \mathbf{s}^{-1}$ & $\begin{array}{l}\text { Dynamic range, } \\
\mathbf{m M}\end{array}$ & $\begin{array}{l}\text { Detection limit, } \\
\boldsymbol{\mu M}\end{array}$ & $\begin{array}{l}\text { Sensitivity, } \\
\mathbf{m A ~} \mathbf{~ M}^{-\mathbf{1}} \mathbf{c m}^{\mathbf{2}}\end{array}$ \\
\hline GOx & $(6.9 \pm 1.2) \times 10^{2}$ & $0.6-32$ & 1.2 & $17.1 \pm 0.4$ \\
LOx & $(1.38 \pm 0.12) \times 10^{2}$ & $19-565$ & 64 & $5.6 \pm 0.8$ \\
ChOx & $(1.8 \pm 0.9) \pm 10^{3}$ & $0.015-1.0$ & 2.3 & $40 \pm 2$ \\
\hline
\end{tabular}

\section{Kinetic studies of mediated enzyme-based biosensors}

Double potential step chronoamperometry was employed for the investigation of the electron transfer process between the enzyme and PTZ, co-immobilised into a sol-gel membrane at the surface of screen-printed electrode, for each of the biosensors under investigation. The double step chronoamperograms were obtained by setting the working electrode potential at $0.2 \mathrm{~V}$ as a forward potential step, where no visible electrode reaction takes place, and then at $0.3 \mathrm{~V}$ as backward potential step, where the catalytic current due to substrate oxidation by mediated enzyme appeared. The current transients (Figure $5 \mathrm{~A}$ ) were recorded in the absence and presence of various concentrations of corresponding substrates. The currents transients did not show a significant difference on the forward potential step with substrate concentration increase, due to the absence of an electrode reaction. The charge transient obtained in the absence of substrate showed an almost symmetrical profile, with almost equal charges being consumed on the forward and backward steps (Inset to Figure $5 \mathrm{~A}$ ). The current transients recorded in the presence of substrate revealed significant increases in currents. The charge value associated with the backward step was greater than that observed with the forward step, illustrating charge consumption due to the catalytic electrode process. Cottrell decay of the electrocatalytic current 
(i.e. the linearity of current $v s t^{-1 / 2}$ ) was not observed, which indicates that the current was not controlled by diffusion of substrate/product to/from the electrode.

Chronoamperometry data collected on the backward potential step was used to evaluate the catalytic rate constant $k$ for the substrate oxidation at enzyme-modified electrode. According to Galus (Galus and Reynolds 1976):

$$
\frac{I_{c}}{I_{l}}=\gamma^{1 / 2}\left[\pi^{1 / 2} \exp \left(\gamma^{1 / 2}\right)+\exp \left(\frac{-\gamma}{\gamma^{1 / 2}}\right)\right]
$$

where $I_{c}$ is the catalytic current of substrate oxidation, $I_{l}-$ the limited current in the absence substrate, and $\gamma=k C_{b} t$ ( $C_{b}$ is the bulk concentration of substrate) is the argument of the error function. In cases where $\gamma$ exceeds 2 , the error function is almost equal to 1 . Therefore, the above equation can be simplified to:

$$
\frac{I_{c}}{I_{l}}=\pi^{1 / 2} \gamma^{1 / 2}=\pi^{1 / 2}\left(k C_{b} t\right)^{1 / 2}
$$

where $t$ is the time elapsed (s). Based on the slope of $I_{c} / I_{l} v s t^{1 / 2}$ plot, $k$ can be obtained for a given substrate concentration. The plots obtained from chronoamperograms on the backward potential step for mediated GOx-modifed electrode are presented in Figure 5 B. From the values of the slopes, an average value calculated for $k$ was $6.9 \pm 1.2 \times 10^{2} \mathrm{M}^{-1} \mathrm{~s}^{-1}$.

The absence of mass transfer control observed under certain conditions shows that the substrate diffusion to the enzyme is faster than the diffusion of PTZ inside the sol-gel membrane. Therefore the mediated reaction becomes a rate determining step. Thus, the value of the catalytic rate constant obtained can be considered as $k_{s}$ in Eq. (2). 

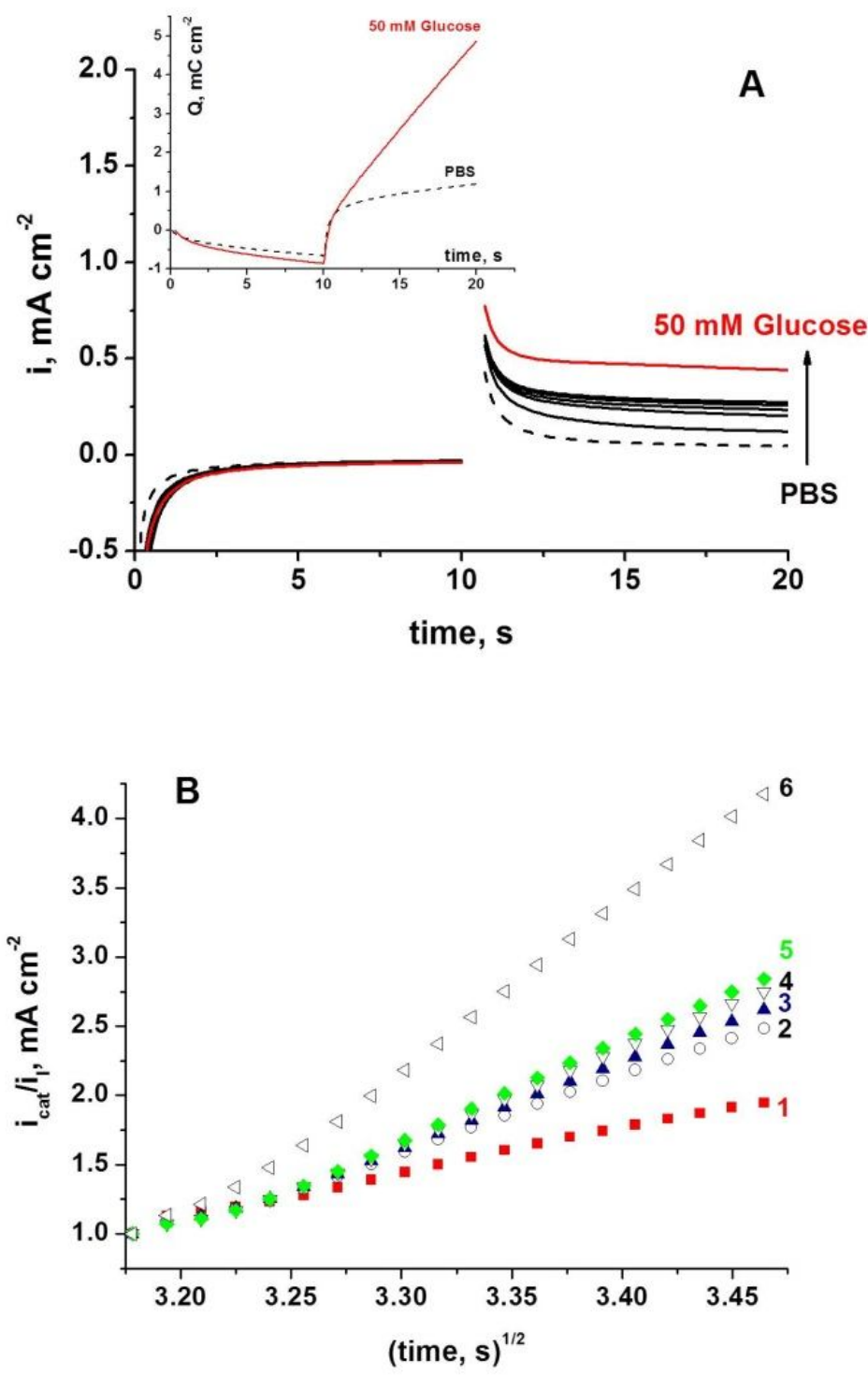

Figure 5. Kinetic study of bioelectrocatalysis of immobilised GOx mediated by PTZ with double-step chronoamperometry. A: Chronoamperogramms of screen-printed electrode modified with enzymecontaining membarene ( $1 \% \gamma$-aminopropylsiloxane, $50 \mathrm{mM}$ phetotiazine and $\left.1.5 \mathrm{mg} \mathrm{mL}^{-1} \mathrm{GOx}\right)$ in the absence (dashed curve) and presence of 5, 10, 15, 20, 25, $50 \mathrm{mM}$ of glucose (forward potential step -0.2 $\mathrm{V}$, backward potential step $\left.0.3 \mathrm{~V}(v s \mathrm{Ag} / \mathrm{AgCl} / 3 \mathrm{M} \mathrm{KCl}), 0.1 \mathrm{M} \mathrm{KCl}, 0.05 \mathrm{M} \mathrm{KH}_{2} \mathrm{PO}_{4} \mathrm{pH} 7.0\right)$. Inset: Charge $v$ s time curves derived from chronoamperometry data collected in the absence (dashed curve) and presence of $50 \mathrm{mM}$ of glucose. B: $I_{\text {cat }} / I_{l} v s t^{1 / 2}$ plot.

Kinetic data obtained by double step chronoamperometry, presented in Table 3, shows that PTZ acts as an efficient mediator for all investigated oxidases. Most previous reports of kinetic studies of mediated bioelectrocatalysis with enzymes are based on electrochemical measurements in homogeneous solutions (Bourdillon et al. 1993); (Kulys et al. 1994); (Heller and Feldman 2008). Double step chronoamperometry allows the kinetic characteristics of biocatalysts to be estimated even in the immobilised state. The apparent second-order rate constant for GOx immobilised into mediator-based sol-gel membrane is smaller than in a 
solution. Thus immobilisation decreases the catalytic activity of enzyme. However, the remaining activity is enough to establish an effective catalytic system for glucose oxidation.

\section{CONCLUSIONS}

The kinetics of the electrocatalytic oxidation of glucose with GOx mediated by unsubstituted PTZ was studied. Due to the low solubility of the mediator in aqueous solutions, water-acetonitrile mixtures with high content of organic solvent were successfully used as a media for electrochemical characterisation of biocatalyst performance. Kinetic analysis of the experimental results obtained with different techniques reveals that the second-order rate constant for reaction between enzyme and mediator is equal to $2.1 \times 10^{4} \mathrm{M}^{-1} \mathrm{~s}^{-1}$ and $7.6 \times 10^{3}$ $\mathrm{M}^{-1} \mathrm{~s}^{-1}$ for water-acetonitrile mixture containing $15 \%$ and $5 \%$ of water, respectively. Unsubstituted PTZ thus delivers superior potential performance among azine-type redox mediators for GOx.

Co-immobilization of PTZ and oxidases such as GOx, LOx or ChOx into a sol-gel membrane on the surface of screen-printed electrode provided a mediated environment for effective catalytic oxidation of corresponding substrates, which resulted in the development of a new family of reagentless biosensors for glucose, lactate and cholesterol, respectively. Advantages include the rapid rate of electron transfer between enzyme and PTZ, providing excellent analytical characteristics, and the water insolubility of the PTZ, which resulted in the

effective confinement of the mediator at the electrode surface to deliver high operational stability.

Second-order rate constants for the reaction between the mediator and variety of oxidases co-immobilised inside a sol-gel membrane were obtained by chronoamperometry. Excellent electrocatalytic activities were observed despite the reagents being immobilised on the surface of electrode. 


\section{ACKNOWLEDGMENTS}

A.N.S thanks the SI for the award of Swedish Institute Scholarship within the Visby Program. 


\section{References}

Andrieux, C.P., Dumas-Bouchiat, J.M., Savéant, J.M., 1980. Journal of Electroanalytical Chemistry $113(1), 1-18$.

Arya, S.K., Datta, M., Malhotra, B.D., 2008. Biosensors and Bioelectronics 23 (7), 1083-1100.

Bard, A.J., 1980. Electrochemical methods : fundamentals and applications / Allen J. Bard, Larry

R. Faulkner. Wiley, New York :.

Bourdillon, C., Demaille, C., Moiroux, J., Saveant, J.M., 1993. Journal of the American Chemical Society 115 (1), 2-10.

Bright, H.J., Gibson, Q.H., 1967. Journal of Biological Chemistry 242(5), 994-1003.

Cardosi, M., Turner, A., 1987. The realization of electron transfer from biological molecules to electrodes. Oxford University Press: New York.

Cash, K.J., Clark, H.A., 2010. Trends in Molecular Medicine 16 (12), 584-593.

Cass, A.E.G., Davis, G., Francis, G.D., Hill, H.A.O., Aston, W.J., Higgins, I.J., Plotkin, E.V., Scott, L.D.L., Turner, A.P.F., 1984. Analytical Chemistry 56 (4), 667-671.

Chakraborty, A., Ahmed, S., Saha, S.K., 2010. Journal of Chemical and Engineering Data 55 (5), 1908-1913.

Cui, X., Li, C.M., Zang, J., Yu, S., 2007. Biosensors and Bioelectronics 22 (12), 3288-3292.

Derbyshire, P.J., Barr, H., Davis, F., Higson, S.P.J., 2012. Journal of Physiological Sciences 62 (6), 429-440.

Dubinin, A.G., Li, F., Li, Y., Yu, J., 1991. Bioelectrochemistry and Bioenergetics 25 (1), 131135.

Fang, C., He, J., Chen, Z., 2011. Sensors and Actuators B: Chemical 155 (2), 545-550.

Flexer, V., Ielmini, M.V., Calvo, E.J., Bartlett, P.N., 2008. Bioelectrochemistry 74 (1), 201-209.

Galus, Z., Reynolds, G.F., 1976. Fundamentals of electrochemical analysis. PWN - Polish Scientific Publishers, Warszawa; Chichester: Ellis Horwood Limited. 
Haberland, D., Landsberg, R., 1966. Berichte der Bunsengesellschaft für physikalische Chemie $70,724$.

Heller, A., Feldman, B., 2008. Chemical Reviews 108 (7), 2482-2505.

Huang, Q., An, Y., Tang, L., Jiang, X., Chen, H., Bi, W., Wang, Z., Zhang, W., 2011. Analytica Chimica Acta 707 (1-2), 135-141.

Jaffari, S.A., Turner, A.P.F., 1997. Biosensors and Bioelectronics 12 (1), 1-9.

Kulys, J., Buch-Rasmussen, T., Bechgaard, K., Razumas, V., Kazlauskaite, J., Marcinkeviciene, J., Christensen, J.B., Hansen, H.E., 1994. Journal of Molecular Catalysis 91 (3), 407-420.

Levich, V.G., 1962. Physicochemical hydrodynamics, Englewood Cliffs, NJ ed. Prentice Hall. Li, G., Liao, J.M., Hu, G.Q., Ma, N.Z., Wu, P.J., 2005. Biosensors an Bioelectronics 20 (10), 2140-2144.

Li, Z., Wang, X., Wen, G., Shuang, S., Dong, C., Paau, M.C., Choi, M.M.F., 2011. Biosensors and Bioelectronics 26 (11), 4619-4623.

Liaudet, E., Battaglini, F., Calvo, E.J., 1990. Journal of Electroanalytical Chemistry 293 (1-2), $55-68$.

Liu, H., Ying, T., Sun, K., Li, H., Qi, D., 1997. Analytica Chimica Acta 344 (3), 187-199.

Liu, J., Guo, C., Li, C.M., Li, Y., Chi, Q., Huang, X., Liao, L., Yu, T., 2009. Electrochemistry Communications 11 (1), 202-205.

May, S.W., 1999. Current Opinion in Biotechnology 10 (4), 370-375.

Motonaka, J., Kamizasa, M., Faulkner, L.R., 1994. Journal of Electroanalytical Chemistry 373 (1-2), 75-81.

Murthy, A.S.N., Anita, 1996. Biosensors and Bioelectronics 11 (1-2), 191-193.

Newman, J.D., Turner, A.P.F., 2005. Biosensors and Bioelectronics 20 (12), 2435-2453.

Nicholson, R.S., 1965. Analytical Chemistry 37 (11), 1351-1355.

Nicholson, R.S., Shain, I., 1964. Analytical Chemistry 36, 706-723.

Noorbakhsh, A., Salimi, A., Sharifi, E., 2008. Electroanalysis 20 (16), 1788-1797. 
Ohara, T.J., Rajagopalan, R., Heller, A., 1993. Analytical Chemistry 65 (23), 3512-3517.

Ohfuji, K., Sato, N., Hamada-Sato, N., Kobayashi, T., Imada, C., Okuma, H., Watanabe, E., 2004. Biosensors and Bioelectronics 19 (10), 1237-1244.

Palleschi, G., Turner, A.P.F., 1990. Analytica Chimica Acta 234 (0), 459-463.

Pereira, A.C., Kisner, A., Tarley, C.R.T., Kubota, L.T., 2011. Electroanalysis 23 (6), 1470-1477.

Randles, J.E.B., 1948. Transactions of the Faraday Society 44 (0), 322-327.

Romero, M.R., Ahumada, F., Garay, F., Baruzzi, A.M., 2010. Analytical Chemistry 82 (13), $5568-5572$.

Sekretaryova, A.N., Vokhmyanina, D.V., Chulanova, T.O., Karyakina, E.E., Karyakin, A.A., 2012. Analytical Chemistry 84 (3), 1220-1223.

Shan, C., Yang, H., Han, D., Zhang, Q., Ivaska, A., Niu, L., 2010. Biosensors and Bioelectronics 25 (5), 1070-1074.

Shan, D., Mousty, C., Cosnier, S., Mu, S.L., 2003. Electroanalysis 15 (19), 1506-1512.

Shul'ga, A.A., Koudelka-Hep, M., de Rooij, N.F., Netchiporouk, L.I., 1994. Analytical Chemistry 66 (2), 205-210.

Solná, R., Dock, E., Christenson, A., Winther-Nielsen, M., Carlsson, C., Emnéus, J., Ruzgas, T., Skládal, P., 2005. Analytica Chimica Acta 528 (1), 9-19.

Tsuge, H., Natsuaki, O., Ohashi, K., 1975. Journal of Biochemistry 78 (4), 835-843.

Tsushima, M., Tokuda, K., Ohsaka, T., 1994. Analytical Chemistry 66 (24), 4551-4556.

Turner, A.P.F., Hendry, S.P., Cardosi, M.F., 1987. Tetrathiafulvalene: a new mediator for amperometric biosensor. Biosensors, Instrumentation and Processing: The World Biotech Report pp. 125-137, 1 ed, London.

Upadhyay, A.K., Ting, T.-W., Chen, S.-M., 2009. Talanta 79 (1), 38-45.

Vidal, J.-C., Espuelas, J., Garcia-Ruiz, E., Castillo, J.-R., 2004. Talanta 64 (3), 655-664.

Wang, Y., Hasebe, Y., 2012. Journal of the Electrochemical Society 159 (5), 110-118.

Wilson, R., Turner, A.P.F., 1992. Biosensors and Bioelectronics 7 (3), 165-185. 
Wopschall, R.H., Shain, I., 1967. Analytical Chemistry 39 (13), 1527-1534.

Yao, Y.-L., Shiu, K.-K., 2007. Electrochimica Acta 53 (2), 278-284.

Yashina, E.I., Borisova, A.V., Karyakina, E.E., Shchegolikhina, O.I., Vagin, M.Y., Sakharov, D.A., Tonevitsky, A.G., Karyakin, A.A., 2010. Analytical Chemistry 82 (5), 1601-1604. 
Supplementary materials

Unsubstituted Phenothiazine as a Superior Water-insoluble Mediator for Oxidases

Alina N. Sekretaryova ${ }^{1,2}$, Mikhail Yu. Vagin ${ }^{2}$, Valerio Beni ${ }^{2}$, Anthony P.F. Turner ${ }^{2 *}$, Arkady A. Karyakin $^{1}$

${ }^{1}$ Faculty of Chemistry, M.V. Lomonosov Moscow State University, Lenin’s Hills, 119991, Moscow, Russia

${ }^{2}$ Department of Physics, Chemistry and Biology, Linköping University, SE-581 83, Linköping, Sweden 

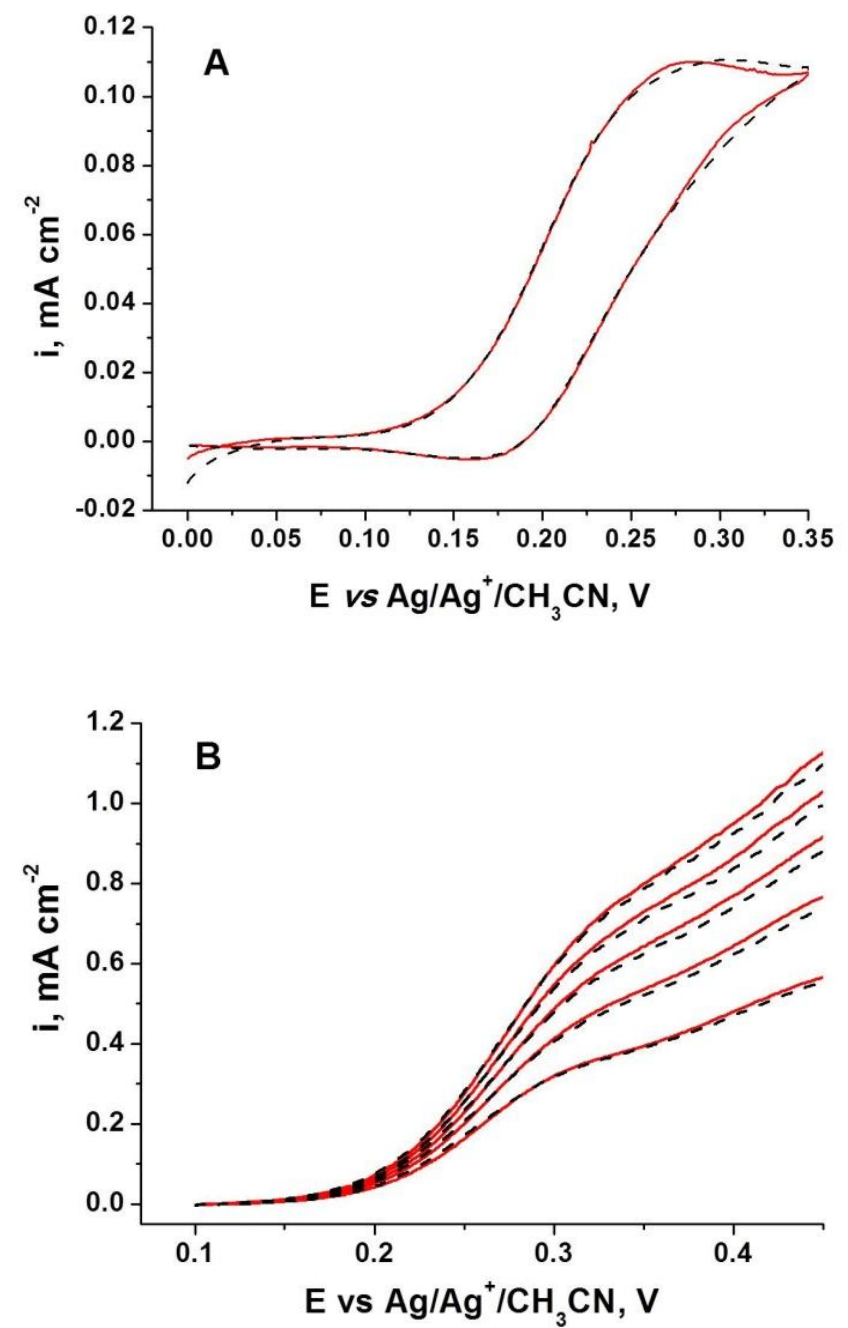

Figure 1 S. Stability of GOx in acetonitrile. A: Difference in cyclic voltammograms recorded at GC in $1 \mathrm{mM}$ phenothiazine and $50 \mathrm{mM}$ glucose in $0.1 \mathrm{M} \mathrm{LiClO}_{4}$ acetonitrile solution $(15 \%$ of water) before (solid line) and after (dashed line) $20 \mathrm{~min}$; scan rate $2 \mathrm{mV} \mathrm{s}^{-1}$. B: Difference voltammograms obtained at rotating GC disk electrode in $1 \mathrm{mM}$ phenothiazine and $10 \mathrm{mM}$ glucose, $1.5 \mathrm{mg} \mathrm{mL}^{-1} \mathrm{GOx}$ in $0.1 \mathrm{M}$ $\mathrm{LiClO}_{4}$ acetonitrile solution (5\% of water) before (solid line) and after (dashed line) $20 \mathrm{~min}$. Scan rate $20 \mathrm{mV} \mathrm{s}^{-1}$, rotating speed 100, 200, 300, 400, $500 \mathrm{rpm}$. 